\title{
從福山對儒家思想的認識看儒家 倫理學的世界前景
}

\section{The World Prospect of}

\section{Confucian Ethics: Fukuyama's}

Views of Confucianism

\author{
王占宇 梁 飛
}

Wang Zhanyu and Liang Fei

\section{Abstract}

Countries and ethnic groups with a Confucian cultural background have performed well during the pandemic. This comparative advantage will inspire efforts to Confucianize ethics. Fukuyama believes that Confucianism as a whole is a defense of authoritarianism but does not pose a major obstacle to liberal

\footnotetext{
王占宇, 山西醫科大學馬克思主義學院副教授, 中國山西, 郵編 : $030001 。$

梁飛, 太原師範學院外語系講師, 中國山西, 郵編：030619。

Wang Zhanyu, Associate Professor, School of Marxism, Shanxi Medical University, Shanxi, China, 030001.

Liang Fei, Lecturer, Department of Foreign Languages, Taiyuan Normal University, Shanxi, China, 030619.
}

《中外醫學哲學》XVIII:2 (2020 年) : 頁 141-145。

International Journal of Chinese \& Comparative Philosophy of Medicine XVIII:2 (2020), pp. 141-145.

C) Copyright 2020 by Global Scholarly Publications. 
democracy, with which it is even compatible in some respects. However, Fukuyama believes that countries led by Confucianism may suffer from disadvantages such as low social capital. Through Fukuyama, the Western opinion leader, we can see the status of Confucian ethics in the spectrum of Western ethics, but there is still a long way to go for Confucian ethics to gain greater recognition worldwide.

正如每次危機一樣, 疫情同樣催人思考。范瑞平教授在〈大 疫當前：訴諸儒家文明的倫理資源〉 中認為, 福山沒有從倫理學 的視角探究國家間抗疫成就迥異的深層原因, 實在是憾事一椿。 但福山對儒家文化的當代願景多有論述。分析福山對儒家思想的 認識, 是觀察大疫背景下, 儒家倫理學在西方倫理學界處境的有 益管道。

\section{一、儒家文化背景國家的抗疫成就， 成為提倡人類倫理學儒化轉向的重要動力}

大疫當前，不同文化、族源下的國家和族盛，應對疫情的方 式不同, 結果迥異。正如范教授所注意到的, 東亞國家在總體應 對疫情相較於西方國家要好。東亞國家的儒家文化背景一定程度 上影響了其抗疫決策。類似的, 美國亞踰感染新冠肺炎的比例明 顯低於其他族盛。究其根源, 有儒家文化背景的亞㓏族群普遍樂 於接受防疫指引遵從規則是重要原因之一。儒家思想強調克己復 禮, 傾向於認同個人利益服從於集體利益。“強調集體勝過個人、 權威勝過自由、義務勝過權利”（Fukuyama 1995, 6.2, 20-33）。 儒家思想甚至強調, 為了追求更大的利益, 個人利益的犧牲是值 得的、必須的、甚至是無條件的。此次抗疫過程中, 多數亞裔主 動配合政府的抗疫舉措。這與其他族㴅對抗疫舉措的反應形成鮮 明對照, 尤其是疫情初期更是如此。隨著歐美各國防疫措施不斷 加碼, 絕大多數普通民眾已開始重新審慎自由和權利的邊界, 並 重新思考個人自由和集體利益之間的相互關係, 更多人開始自覺 
配合政府抗疫措施。相應地，儒家文明背景下國家的抗疫表現引 人思考, 儒家思想中的權利義務説的生存空間在西方倫理論學中 一定程度得以拓展。亨廷頓認為, 一個國家取得的經濟成就通常 會 “鼓勵該社會的人們對自己遺產充滿信心並對自己的文化開始 自信（Huntington 1996）”。事實上，抗疫成就同樣可以催生儒 家文化圈的文化自信。但不可否認, 從西方原則主義倫理學向儒 家美德倫理學的轉向，仍有大量工作要做。

\section{二、福山對儒家文化的認知, 是探究西方主要思想界 進而西方社會心態的一個有益通道}

科學主義、原則主義、契約主義等當今西方倫理學的主要觀 念，與西方政治領域的自由、民主、法治等所謂的普世價值之間 存在著密切關係。福山認為, 民主的產生和璋固有賴於四個遞進 的層面：意識形態、制度、市民社會和文化。其中最深層次也是 變化最慢的就是文化，它包括家庭結構、宗教信仰、道德價值、 倫理認知等（Fukuyama 1995，6.1，7-14）。不難看出, 福山雖然 是政治科學家, 但他不能不研究文化, 不能忽視倫理學等對社會 制度的影響。因此, 在探討儒家倫理學在多大程度上可能成為西 方倫理學的補充甚至是替代, 通過考察福山這位西方思想界意見 領袖對儒家思想的認知, 是可能的路徑之一。

一方面，福山認為儒家思想是為威權主義辯護的。首先，普 遍認為傳統儒家思想是不民主的甚至是反民主的。儒家思想認為 個人天生是不自由的; 儒家強調綱常倫理、克己復禮、尊敬長輩、 遵從權威; 對和諧和協作的偏好勝過分歧和競爭。儒家思想的社 會缺乏對抗國家權力的傳統。這種對個人自由和權利的限制, 與 主張個性張揚、人格獨立、權利意識的西方文化傳統顯然存在衝 突。其次, 儒家強調德治或者人治勝過法治。以祖先崇拜為重要 特徵的儒家文化, 阻礙了形成共同認可的超然宗教。因為超然宗 教的缺失, 法律不被視為有關社會公正的共識, 是統治階級對被 
統治者的單方面約束, 而統治階級本身不受法律制約, 這樣的國 家就不是法治國家而是人治的國家。再次, 儒家強調道義責任。 傳統的儒家強調帝王和統治者對其治理的國家存在道義上的責 任, 強調通過教育來培養統治者的道德義務。即統治者必須順天 應人, 承擔自己的使命, 提供善治, 要努力創建國泰民安的禮儀 之邦。西方文化中強調的正式的負責制是程式性的。

另一方面, 福山認為儒家思想具有很強的政治相容性。首先, 日常儒家思想可以與廣泛的政權形式相容。政治儒家思想是規範 特定等級的政治權威的教義, 這種權威以皇帝和正統為中心。日 常儒家思想規範的是家庭關係, 工作倫理等等 (Fukuyama 1997, 146-149）。政治儒家思想和日常儒家思想可以相互獨立。政治儒 家思想與民主自由思想格格不入, 日常儒家思想卻可與廣泛的政 權形式共存。其次, 重視教育、考試制度及儒家的包容性對自由 民主是有益的。儒家思想主導的東亞社會普遍輕視商業和體力勞 動, 再加上沒有世襲官位制, 參加科考成為改變個人和家族命運 的主要途徑。這種基於個人能力的、帶有潛在平等主義的創舉, 促成了儒家文化圈普遍重視教育。這種對教育的重視對民主政治 是有益的。一定水準的讀寫能力是人們關心國家大事並進而參與 民主討論的前提。教育通常會導致人們更加富有、更加關心非經 濟事務如政治認同和政治參與。公平的科舉考試可以促進社會公 平、推動人才向上流動, 可以營造經過個人努力獲得成功的平等 競爭氛圍, 這也是民主選舉所需要的。再次, 儒家強調民本, 有 反獨裁的傾向。儒學者認為自己是天子的子民, 同時認為自己是 文明的承載著和捍衛者; 不僅沒有把自身完全定位於為統治階級 維護統治秩序, 相反致力於對專制皇權的觀念約束, 甚至是致力 於對皇權的馴服和規範。儒家還主張 “愛民”，即統治者必須關 心人民的利益和疾苦, 輕賦税、慎刑罰, 施仁政, 順天命。順天 命就是要順應人民的意願, 遵從人命的選擇。 


\section{三、儒家倫理學在世界範圍內得到更大程度的認可 仍然是一條漫長的道路}

福山認為儒家思想天然地存在著與自由民主相悖的因素，但 並不妨礙深受儒家思想影響的國家和地區的民主化。當然, 更好 的前景是這些國家可以擺脱儒家思想的影響。因為, 儒家強調家 庭的重要性, 家庭、擴大的家族以及同鄉之間存在著高度的信任 關係, 一旦離開這個圈子，信任度驟然降低。這種低社會資本的 國家中，不利於形成大型企業。為了擺脱這種情況，國家必然介 入經濟生活, 制定出口導向的發展戰略, 從長遠來看, 出口導向 的發展戰略不僅難以為繼而且損人不利己（Fukuyama 2010）。同 時, 過多地強調儒家思想, 又容易推高這些國家的民族主義傾向。

福山對儒家思想在儒家文化圈的發展前景態度謹慎。當然， 大疫當前, 福山堅持認為的歷史終結於市場取向的資本主義自由 民主國家遭遇重創，我們有理由對儒家倫理在世界範圍內獲得更 大程度的認可保持樂觀。

\section{參考文獻 References}

范瑞平：〈大疫當前：訴諸儒家文明的倫理資源〉, 《中外醫學哲學》, 2020 年, 第 XVIII 卷, 第 2 期, 頁 81-107 •FAN Ruiping. “Combating the Coronavirus Pandemic: An Appeal to Confucian Ethical Resources," International Journal of Chinese \& Comparative Philosophy of Medicine, XVIII: 2 (2020), pp. 81-107.

Fukuyama, Francis. "Confucianism and Democracy," Journal of Democracy, Vol.6, Issue 2, 1995.

Fukuyama, Francis. "The Primacy of Culture," Journal of Democracy, Vol. 6, Issue 1, 1995.

Fukuyama, Francis. "The Illusion of Exceptionalism," Journal of Democracy, Vol.8, Issue 3, 1997.

Fukuyama, Francis, Henry Paulson. "China, Wall Street, and the Financial Crisis," Christian Science Monitor, March 20, 2010.

Huntington, Samuel P. "The West: Unique, Not Universal," Foreign Affairs, No.6 (Nov./Dec.), 1996. 